\title{
ESTRATÉGIAS PARA PRODUÇÃO DE FORRAGEM UTILIZANDO MILHO, SORGO E MILHETO NA REGIÃO CENTRAL DE MINAS GERAIS
}

\author{
EDUARDO DE PAULA SIMÃO ${ }^{1}$, MIGUEL MARQUES GONTIJO NETO², \\ EDSON APARECIDO SANTOS², VINICIUS GUSTAVO FREIRE BARCELOS ${ }^{1}$
}

${ }^{1} U F S J$, Sete Lagoas, MG, Brasil, eduardosimao.agro@yahoo.com.br, vinicius.gustav0@hotmail.com

${ }^{2}$ Embrapa Milho e Sorgo, Sete Lagoas, MG, Brasil, miguel.gontijo@embrapa.br, edsonapsant@yahoo.com.br

Revista Brasileira de Milho e Sorgo, v.14, n.1, p. 75-87, 2015

RESUMO - Objetivou-se, com este trabalho, avaliar parâmetros qualitativos e quantitativos de milho, sorgo e milheto na região Central de Minas Gerais para produção de forragem. Foram analisadas seis estratégias de produção: milho; sorgo; milho na safra e milheto (cv. ADR500) na safrinha; milho na safra e milheto (cv. BRS1503) na safrinha; sorgo e manutenção da rebrota na safrinha; e sorgo com manutenção da rebrota sem adubação. Avaliaram-se a produtividade de matéria seca e os teores de proteína bruta, fibras em detergente ácido e neutro. O tratamento com o plantio de sorgo em outubro, e condução da rebrota, utilizando-se adubação de cobertura com nitrogênio apresentou o melhor desempenho produtivo. Por outro lado, o plantio de sorgo na safra, e não condução da rebrota, possibilitou os piores resultados. Adicionalmente, a utilização de milheto, como cultura posterior ao milho, também promoveu as melhores produtividades.

Palavras-chave: BRS 1503; ADR 500; adubação nitrogenada.

\section{EVALUATION OF STRATEGIES FOR FORAGE PRODUCTION USING MAIZE, SORGHUM AND MILLET IN THE CENTRAL REGION OF MINAS GERAIS, BRAZIL}

\begin{abstract}
The purpose of this study was assessing qualitative and quantitative parameters of corn, sorghum and millet for forage production, in the central region of Minas Gerais, Brazil.. Six strategies of production were analyzed: corn (1) and sorghum (2) sown in October; corn planting in October plus millet, cultivars ADR500 (3) and BRS1503 (4) sown after corn harvest; sorghum planting in October plus maintenance of regrowth with nitrogen fertilization (5) and without fertilization (6). Productivity of dry matter and contents of crude protein, acid and neutral detergent fiber were evaluated. The most appropriate strategy for the region was the planting of sorghum in October and maintenance of regrowth with nitrogen fertilization, however, planting millet after corn harvest, regardless of the variety, also gave high yields.
\end{abstract}

Key words: BRS 1503; ADR 500; nitrogen fertilization. 
A atividade pecuária brasileira é destaque nos mercados interno e externo. Atualmente, o país é o maior exportador de carne e possui o maior rebanho comercial, com aproximadamente $210 \mathrm{mi}-$ lhões de cabeças. O principal modelo de criação é por meio da utilização de pastagens extensivas e suplementação mineral. Dessa forma, em função da grande quantidade de animais, estima-se que $20 \%$ do território nacional, cerca de 180 milhões de hectares, sejam ocupados pelas espécies forrageiras (Batistella et al., 2011).

As pastagens são, portanto, a forma mais econômica de acesso ao alimento pelo rebanho. Porém, de acordo com as condições climáticas, a oferta é limitada durante parte do ano, principalmente em regiões com períodos de chuva definidos. Por esse motivo, os gastos com alimentação podem chegar a $40 \%$ dos custos totais da produção pecuária e a baixa nutrição dos animais compromete a competitividade do pecuarista (Lopes et al., 2011; Azevedo et al., 2011).

O estado de Minas Gerais, principal produtor de leite brasileiro, tem $43 \%$ de seu território ocupado por pastagens, área próxima a 25 milhões de hectares. Nesse estado, a região Central comporta um rebanho aproximado de 1,22 milhão de animais (SEAP, 2009) e, de acordo com as características climáticas, a disponibilidade de alimento é o fator mais importante da atividade, principalmente entre os meses de março e outubro, quando a baixa ocorrência de chuvas (Ferreira \& Souza, 2011) limita o acúmulo de biomassa pelas plantas e compromete economicamente a atividade (Bernardes et al., 2013; Borges et al., 2013).

Uma estratégia utilizada pelos produtores é a produção de silagem de milho, em cultivo no período de chuvas (outubro a março), e fornecimento ao rebanho no período de baixa produtividade das pastagens (Bernardes et al., 2013). Esse procedimento aumenta os custos de produção (Lopes et al., 2011; Azevedo et al., 2011) e é considerado pouco sustentável, uma vez que a área agrícola fica ocupada com a cultura apenas nos meses chuvosos. Adicionalmente, a alimentação do rebanho é prejudicada em função da baixa oferta de silagem.

Nesse sentido, uma alternativa para aumentar o fornecimento de alimento é a produção de forragem posterior ao cultivo de milho. No Sudeste do estado de Goiás, Silva et al. (2007), com o propósito de avaliar a produção de sorgo (Sorghum bicolor L. Moench) na safrinha para alimentação bovina, verificaram que a gramínea em questão é indicada por acumular grande quantidade de biomassa, mesmo em condições edafocliámaticas adversas. Neumann et al. (2004) também indicam a utilização de sorgo para bezerros confinados, destacando-se qualidade nutricional igual à silagem produzida a partir do milho.

Além do regime de chuvas, concentrado entre os meses de outubro e março, características relacionadas ao fotoperíodo também comprometem a produção de milho quando semeado distante dos meses de outubro ou novembro. Nesse sentido, é necessário que a forrageira a ser produzida após o milho seja produtiva e pouco influenciada por esses fatores adversos. Além do sorgo, outra cultura indicada é o milheto (Pennisetum glaucum (L.) R. Brown).

De acordo com Durães \& Magalhães (2005), essa gramínea é eficiente no acúmulo de biomassa, pois tem capacidade diferenciada na utilização dos recursos e fatores do ambiente. Além disso, a rusticidade na produção propicia vantagens econômicas ao produtor. Em função disso, Porto et al. (2012) relatam que a utilização de silagem de milheto é equivalente à de milho na definição de características da carcaça dos animais. 
Destaca-se, portanto, que a possibilidade de utilizar outra cultura após a utilização do milho é prática que agrega valores à propriedade e segurança na produção pecuária. Principalmente se a cultura em questão for equivalente ao milho em atributos quantitativos e qualitativos. Adicionalmente, a comparação de estratégias para otimizar a produção de biomassa vegetal, a partir das plantas de sorgo ou milheto, é recomendada a fim de definição da melhor tecnologia para a região de estudo.

Dentre os fatores envolvidos nas técnicas de produção, a definição sobre a variedade a ser utilizada e decisões sobre a utilização de insumos, como adubação (principal item na análise econômica de produção), devem ser considerados na escolha da melhor estratégia para aumento no fornecimento de forragem.

Nesse sentido, objetivou-se com o trabalho avaliar a produção e a qualidade de forragem na região Central de Minas Gerais em diferentes estratégias, utilizando-se milho, sorgo forrageiro e milheto.

\section{Material e Métodos}

O trabalho foi conduzido na área experimental da Embrapa Milho e Sorgo, em Sete Lagoas ,MG. As coordenadas geográficas da área são $19^{\circ}$
26'39,7" S e $44^{\circ} 10^{\prime \prime} 02,22^{\prime \prime} \mathrm{O}$, em altitude de 705 m. Adicionalmente, a classificação do clima é Aw (Köppen), com inverno seco e temperaturas médias inferiores próximas a $16{ }^{\circ} \mathrm{C}$ e médias superiores acima de $28{ }^{\circ} \mathrm{C}$. As chuvas se concentram de novembro a março, com média próxima a $200 \mathrm{~mm}$. Por outro lado, nos outros meses esse valor é de $30 \mathrm{~mm}$ (Ferreira \& Souza, 2011).

Após definição da área, foram coletadas amostras de solo que apresentaram as seguintes características químicas: (profundidade de 0-20 cm): pH (água) - 6,1; P e K (mg dm $\left.{ }^{-3}\right)$ - 43,3 e 115,3, respetivamente; $\mathrm{SB}, \mathrm{Ca}, \mathrm{Mg}, \mathrm{Al}$ e $\mathrm{H}+\mathrm{Al}\left(\mathrm{cmolc} \mathrm{dm}^{-3}\right)$ - 5,5, 4,7, 0,5, 0,0 e 3,4, respetivamente; CTC - 8,9; V (\%) - 62; M.O. (dag $\left.\mathrm{kg}^{-1}\right)$ - 2,2; Fe, Cu, $\mathrm{Zn}$ e $\mathrm{Mn}$ $\left(\mathrm{mg} \mathrm{kg}^{-1}\right)-65,5,1,4,4,2$ e 16,9, respectivamente. (Profundidade de 20 a $40 \mathrm{~cm}$ ): $\mathrm{pH}$ (água) - 6,6; $\mathrm{P}$ e $\mathrm{K}\left(\mathrm{mg} \mathrm{dm}^{-3}\right)-15,6$ e 70,8, respetivamente; $\mathrm{SB}, \mathrm{Ca}$, $\mathrm{Mg}, \mathrm{Al}$ e $\mathrm{H}+\mathrm{Al}\left(\mathrm{cmolc} \mathrm{dm}^{-3}\right)-5,3,4,7,0,4,0,0$ e 2,7, respetivamente; CTC - 8,0; V (\%) - 65,9; M.O. (dag $\left.\mathrm{kg}^{-1}\right)$ - 1,8; Fe, Cu, Zn e Mn (mg kg $\left.{ }^{-1}\right)$ - 131,4, 1,8, 5,8 e 36,5 , respectivamente.

Foram definidos seis tratamentos quanto à produção de forragem (Tabela 1), de tal forma que foram utilizadas duas culturas na safra (milho e sorgo forrageiro com plantios em 16 de outubro de 2012) e

TABELA 1. Apresentação dos tratamentos testados quanto à avaliação de estratégias para produção de silagem. Plantio safra: 16-10-2012, safrinha: 18-02-2013. Sete Lagoas, MG

\begin{tabular}{ccc}
\hline Tratamento & Safra & Safrinha \\
\hline 1 & Milho & Pousio \\
2 & Sorgo & Pousio \\
3 & Milho & Milheto ADR 500 \\
4 & Milho & Milheto BRS 1503 \\
5 & Sorgo & Rebrota adubado \\
6 & Sorgo & Rebrota não adubado \\
\hline
\end{tabular}


duas na safrinha (rebrota do sorgo e plantio de duas variedades de milheto em 18 de fevereiro de 2013).

Para semeio das culturas na safra em sistema de plantio direto, houve dessecação da área utilizando-se glyphosate $\left(1,08 \mathrm{~kg} \mathrm{ha}^{-1}\right)$ aos 30 dias de antecedêncida. A adubação inicial foi composta por $450 \mathrm{~kg} \mathrm{ha}^{-1}$ de NPK (08-28-16) e as sementes foram previamente tratadas com imidacloprido + tiodicarb $\left(2,25+6,75 \mathrm{~g} \mathrm{~kg}^{-1}\right)$ e carboxina + tiram $\left(0,6+0,6 \mathrm{~g} \mathrm{~kg}^{-1}\right)$. Para o plantio de milho, foi utilizada a variedade AG8088 PRO em espaçamento de $0,7 \mathrm{~m}$ entrelinhas e estande de 70.000 plantas $\mathrm{ha}^{-1}$. Para sorgo, foi utilizada a variedade BRS 655 no mesmo espaçamento do milho e estande de 140.000 plantas ha-1 ${ }^{-1}$ Aos 20 dias após a emergência, foram aplicados os herbicidas atrazine, na dose de 2,0 $\mathrm{kg} \mathrm{ha}^{-1}$, e nicosulfuron (60 $\left.\mathrm{g} \mathrm{ha}^{-1}\right)$ nas parcelas de milho e apenas atrazine nas parcelas de sorgo. Além disso, foi realizada adubação de cobertura, dividida em duas épocas: 25 e 35 dias após plantio, com $90 \mathrm{~kg} \mathrm{ha}^{-1}$ de $\mathrm{N}$ e $70 \mathrm{~kg} \mathrm{ha}^{-1}$ de 30-0020 (NPK), respectivamente.

A área de cada parcela correspondeu a seis fileiras com $6 \mathrm{~m}$ de comprimento $\left(25,2 \mathrm{~m}^{2}\right)$. Porém, a área efetivamente utilizada nas análises correspondeu a $4 \mathrm{~m}$ centrais das duas linhas do interior da parcela $\left(5,6 \mathrm{~m}^{2}\right)$. Nessa área, aos 92 dias após o plantio, as plantas de milho e sorgo foram cortadas a 0,2 $\mathrm{m}$ do nível do solo e separadas as porções folha + colmo e espiga (ou panícula) para determinações dos teores de massa seca, proteína bruta, fibras em detergente neutro e fibras em detergente ácido, de acordo com Van Soest et al. (1991) e Silva \& Queiroz (2006).

Após a colheita dessas plantas, parcelas foram mantidas em pousio (tratamentos 1 e 2), em área de milho foram semeadas duas variedades de milheto (tratamentos 3 e 4) e em área de sorgo, após o corte, houve adubação da rebrota (tratamento 5) ou as mesmas foram cultivadas sem a adição do nutriente (tratamento 6).

Nas parcelas destinadas ao plantio de milheto, foi realizada aplicação de glyphosate $(1,8 \mathrm{~kg}$ $\mathrm{ha}^{-1}$ ) aos 17 dias antes do plantio, que foi realizado aos 19 dias após a colheita do milho (18/02/2013). Foram utilizadas as variedades ADR 500 e BRS 1503.

Antes da semeadura, as sementes foram tratadas com os inseticidas imidacloprido + tiodicarbe $\left(2,25+6,75 \mathrm{~g} \mathrm{~kg}^{-1}\right.$ de sementes $)$ e com os fungicidas carboxina + dimetilditiocarbamato $(0,6+0,6$ $\mathrm{g} \mathrm{kg}^{-1}$ de sementes). A adubação de plantio utilizada foi de $200 \mathrm{~kg} \mathrm{ha}^{-1}$ de NPK (08-30-16) e, como cobertura, aos 30 dias após a emergência, foram aplicados $31,5 \mathrm{~kg} \mathrm{ha}^{-1}$ de $\mathrm{N}$, utilizando-se ureia. Finalmente, aos 80 dias após o plantio, foram realizadas as avaliações quantitativas e qualitativas utilizadas nas plantas de milho e sorgo.

$\mathrm{Na}$ área de rebrota do sorgo, houve aplicação de atrazine $\left(1,5 \mathrm{~kg} \mathrm{ha}^{-1}\right)$ aos 12 dias após a colheita e, 28 dias após, houve adubação na linha, utilizando-se $47 \mathrm{~kg} \mathrm{ha}^{-1}$ de $\mathrm{N}$ na forma de ureia (tratamento 5), mesma adubação nitrogenada utilizada no milheto. Além disso, foram mantidas parcelas com sorgo em rebrota, porém apenas com a aplicação do herbicida (tratamento 6). Finalmente, foram realizadas as mesmas avaliações anteriormente citadas.

Durante todo o período de montagem e condução dos ensaios, os dados referentes a precipitações e temperaturas máxima e mínima foram monitorados (Figuras 1 e 2).

$\mathrm{O}$ experimento foi montado em esquema de blocos casualizados, com cinco repetições. 


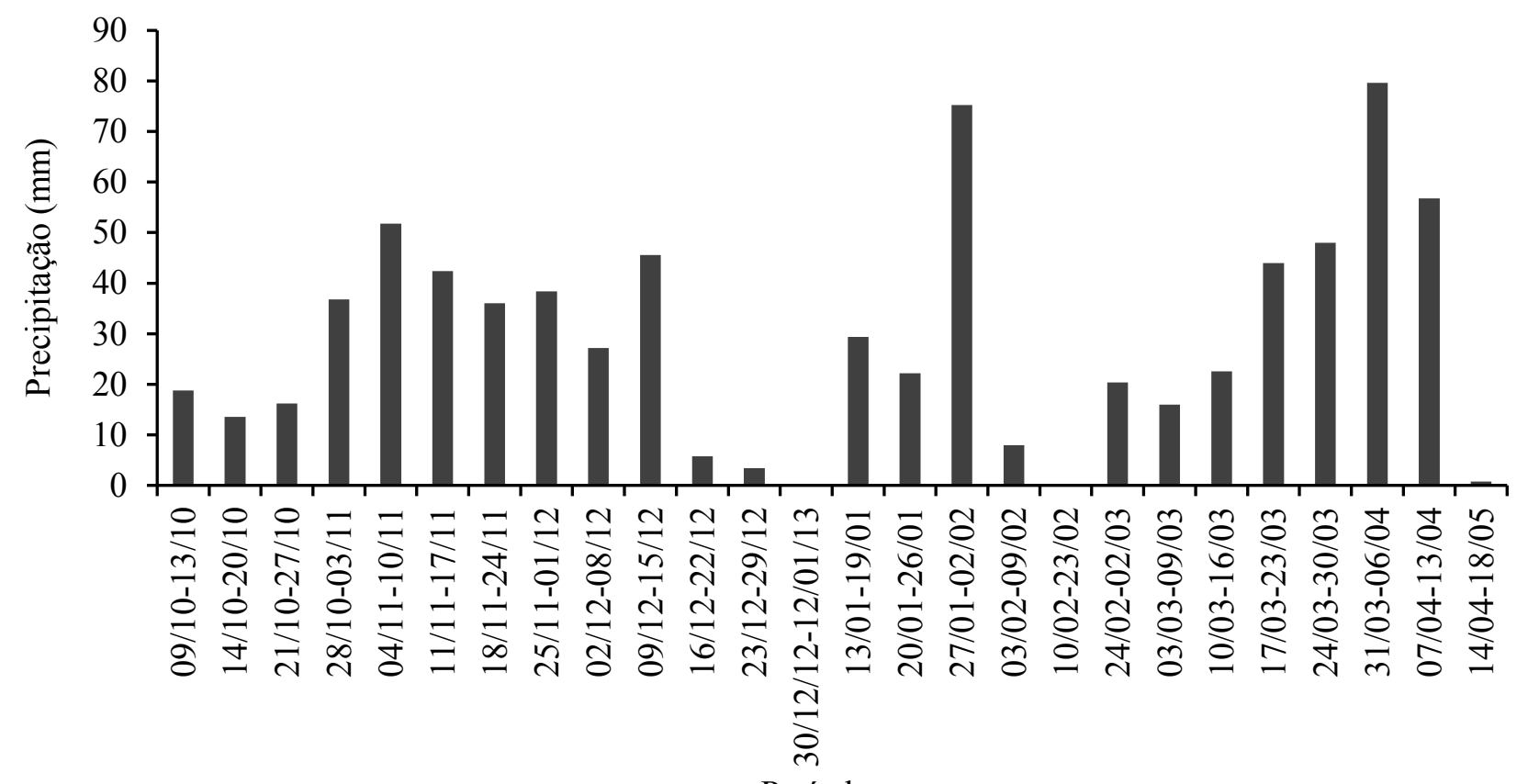

Período

FIGURA 1. Precipitação média na área dos experimentos no período de condução dos ensaios de safra e safrinha (outubro/2012 a maio/2013). Estação Meteorológica da Embrapa Milho e Sorgo. Sete Lagoas, MG.

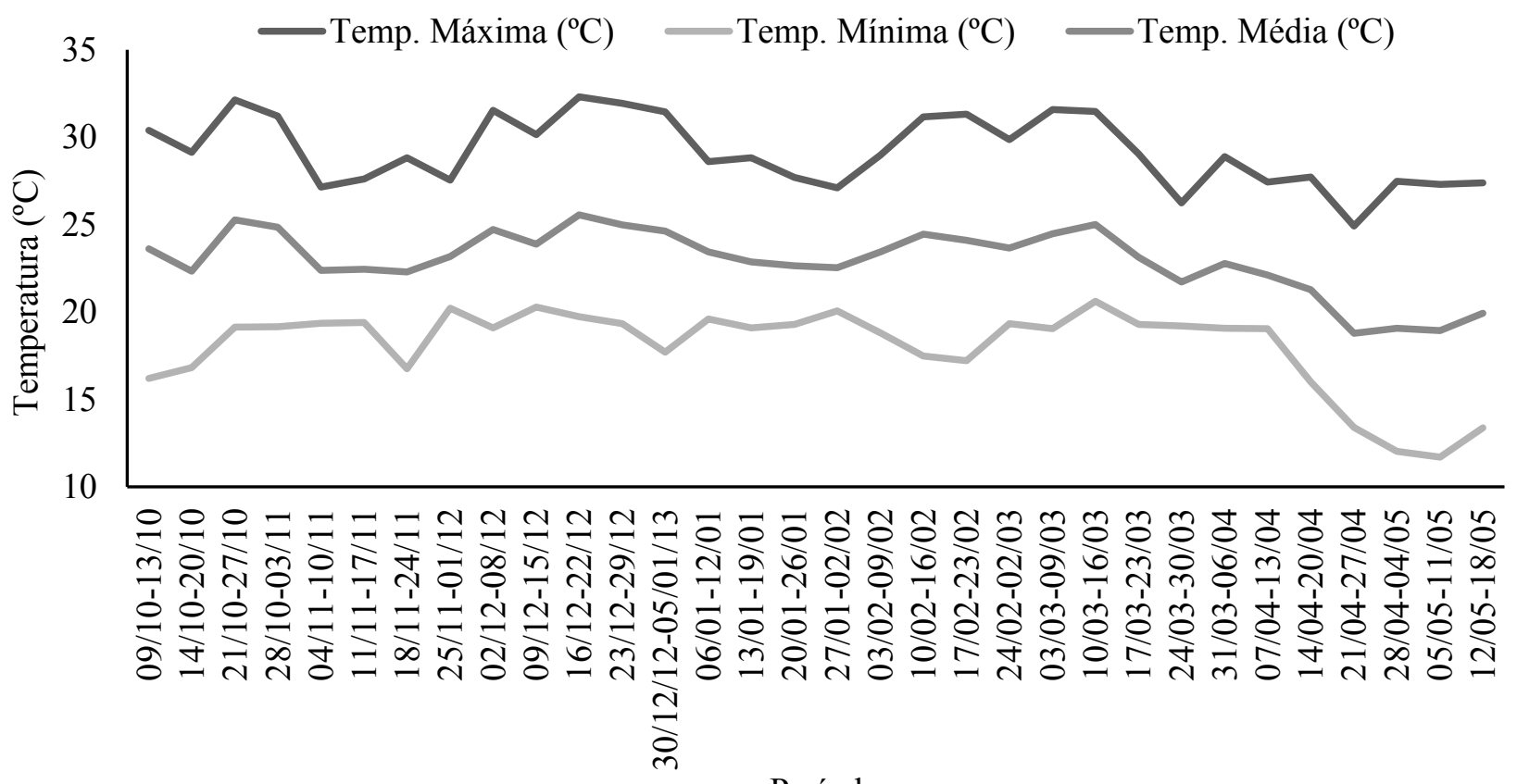

Período

FIGURA 2. Dados de Temperatura (Temp.) na área dos experimentos no período de condução dos ensaios de safra e safrinha (outubro/2012 a maio/2013). Estação Meteorológica da Embrapa Milho e Sorgo. Sete Lagoas, MG. 
Considerando os seis tratamentos, foi adotada a adição dos parâmetros avaliados (safra + safrinha). Todas as médias foram submetidas à análise de variância e as diferenças, quando significativas, foram comparadas pelo teste de Tukey $(\mathrm{P} \leq 0,05)$.

\section{Resultados e Discussão}

Avaliando-se primeiramente a produção de milho e sorgo cultivados na safra, observou-se que a proporção de matéria seca na primeira cultura foi maior, independente da porção da planta avaliada. Por outro lado, os teores de proteína bruta e fibra em detergente ácido são maiores em sorgo. Finalmente, para o parâmetro fibra em detergente neutro, as plantas possuem os mesmos teores (Tabela 2).

De acordo com Oliveira et al. (2010), é recomendada a utilização de plantas com aproximadamente $30 \%$ de matéria seca para a ensilagem. No entando, em função de adversidades climáticas regionais e para fins de comparação com o milho, a colheita do sorgo antes do período convencionalmente recomendado para ensilagem proporcionou teor de fibra em detergente neutro semelhante àquele encontrado em milho.Por outro lado, a porcentagem de proteínas foi maior em sorgo em função da diluição em menor conteúdo de matéria seca.

Os elevados teores de FDN nas plantas podem ter sido influenciados pela adubação à qual as culturas foram submetidas, conforme relatado por Dias et al. (2000). Adicionalmente, considerando a recomendação de adubação para as culturas (Ribeiro et al., 1999), em função dos teores de fósforo e potássio no solo, a adição desses nutrientes foi além dos valores recomendados.

Por outro lado, a baixa concentração de FDA observada pode ser reflexo do baixo teor de MS no momento do corte. Em trabalho realizado por Benetti (2008), foi observada relação inversa entre o incremento de nitrogênio, as plantas de Brachiaria brizanha cv. Marandu e o teor de FDA. Tal fato destaca a importância da adubação nitrogenada para as gramíneas forrageiras, uma vez que para alimentação o material não pode ter mais que $40 \%$ de FDA, pois há comprometimento direto no consumo (Nussio, 1998).

A proporção da espiga de milho na massa de forragem foi mais que duas vezes a proporção de

TABELA 2. Parâmetros (Par.) fitotécnicos: Massa Seca (MS); Proteína Bruta (PB); Fibra em Detergente Neutro (FDN); e Fibra em Detergente Ácido (FDA) de plantas de milho e sorgo cultivadas para produção de silagem em Sete Lagoas, MG.

\begin{tabular}{|c|c|c|c|c|c|c|c|c|c|}
\hline \multirow{2}{*}{ Par. $^{1}$} & \multicolumn{3}{|c|}{ Planta inteira } & \multicolumn{3}{|c|}{ Folha e colmo } & \multicolumn{3}{|c|}{ Espiga ou panícula } \\
\hline & Milho & Sorgo & $\mathrm{CV}$ & Milho & Sorgo & $\mathrm{CV}$ & Milho & Sorgo & $\mathrm{CV}$ \\
\hline & & & & & $---\%$ & & & & ----- \\
\hline MS & $27,0 \mathrm{a}$ & $17,3 \mathrm{~b}$ & 5,5 & $22,5 \mathrm{a}$ & $16,8 \mathrm{~b}$ & 9,7 & $43,2 \mathrm{a}$ & $25,9 \mathrm{~b}$ & 6,4 \\
\hline PB & $9,3 \mathrm{~b}$ & $12,4 \mathrm{a}$ & 10,5 & $7,6 \mathrm{~b}$ & $12,7 \mathrm{a}$ & 13,6 & $9,4 \mathrm{~b}$ & $13,0 \mathrm{a}$ & 6,9 \\
\hline FDN & $71,3 \mathrm{a}$ & $71,8 \mathrm{a}$ & 1,9 & $74,3 \mathrm{a}$ & $71,1 \mathrm{a}$ & 4,8 & $70,1 \mathrm{a}$ & $69,2 \mathrm{a}$ & 15,0 \\
\hline FDA & $34,6 \mathrm{~b}$ & $45,4 \mathrm{a}$ & 3,8 & $41,7 \mathrm{~b}$ & $44,3 \mathrm{a}$ & 5,5 & $17,1 \mathrm{~b}$ & $34,7 \mathrm{a}$ & 5,3 \\
\hline
\end{tabular}

${ }^{1}$ Médias seguidas pela mesma letra, minúscula na linha, não diferem entre si pelo teste de Tukey $(\mathrm{P} \leq 0,05)$. 
panícula de sorgo, refletindo em uma melhor qualidade de forragem do milho, visto que os parâmetros qualitativos das forragens estão diretamente relacionados a essa proporção, pois os grãos compõem a parte mais nutritiva e esse quesito se dá em função do melhoramento genético no qual a variedade foi desenvolvida (Paziani, 2009).

Apesar da colheita das plantas de sorgo antes do período recomendado e com baixo teor de matéria seca, as mesmas apresentaram aproximadamente $70 \%$ da produtividade de massa seca em relação ao milho. Destaca-se ainda que a produtividade de proteína bruta, e de fibras em detergente ácido em sorgo, foram semelhantes àquelas encontradas em milho (Tabela 3), justificando a utilização do sorgo na região de estudo, principalmente considerando aspectos econômicos, como gastos com sementes, adubação e defesa fitossanitária.

Com relação aos cultivos da safrinha, foi realizada a colheita das plantas em ponto indicado para ensilagem em relação ao teor de matéria seca (próximo a 30\%). Nesse ponto, o milheto (BRS 1503) apresentou maior teor de proteína bruta com relação ao sorgo. Além disso, o milheto ADR 500 apresentou os maiores teores de fibra em detergente ácido e o sorgo, quando adubado, apresentou maior teor de fibras em detergente neutro com relação ao milheto BRS 1503 (Tabela 4).

Em análise das produtividades, foi observado que o cultivo da rebrota de sorgo, com adubação, proporcionou os maiores valores (cerca de $40 \%$ maiores em relação aos outros tratamentos). Entretanto, os teores de proteína da forragem foram superiores apenas ao tratamento de sorgo não adubado. Os teores de fibras em detergente ácido e neutro foram proporcionais ao maior acúmulo de massa seca no cultivo do sorgo de rebrota com adubação (Tabela 5).

O corte precoce do sorgo na safra, com apenas $17 \%$ de matéria seca e com produtividade correspondente a $70 \%$ em relação àquela de milho, pode ter afetado positivamente a produção de massa seca do segundo corte, principalmente quando houve adubação, o que possibilitou a colheita de 11,2 ton $\mathrm{ha}^{-1}$ de matéria seca. Plantas cortadas precocemente, com possibilidade de rebrota, possuem sistema radicular mais vigoroso, o que está diretamente relacionado à maior absorção de água e fertilizantes. Adicionalmente, as plantas reiniciaram o acúmulo de massa na parte aérea em período com temperatura e precipitações adequadas às exigências fisiológicas (Figuras 1 e 2).

TABELA 3. Proporções de Folha e Colmo $(F+C)$ e Espiga ou Panícula (E ou P) e Produtividade de Matéria Seca (PMS), Proteína Bruta (PPB), Fibras em Detergente Neutro (PFDN) e Ácido (PFDA) de plantas de milho e sorgo cultivadas para produção de silagem em Sete Lagoas, $\mathrm{MG}$

\begin{tabular}{|c|c|c|c|c|c|c|}
\hline Cultura $^{1}$ & $\mathrm{~F}+\mathrm{C}$ & E ou P & PMS & PPB & PFDN & PFDA \\
\hline & \multicolumn{3}{|c|}{------------------ \% ------------------ } & \multicolumn{3}{|c|}{ 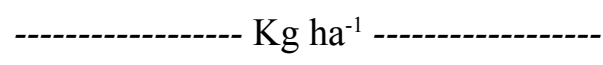 } \\
\hline Milho & $46,49 \mathrm{~B}$ & $53,51 \mathrm{~A}$ & $20.211 \mathrm{~A}$ & $1.903 \mathrm{~A}$ & $14.411 \mathrm{~A}$ & $6.991 \mathrm{~A}$ \\
\hline Sorgo & $80,58 \mathrm{~A}$ & $19,42 \mathrm{~B}$ & $13.905 \mathrm{~B}$ & $1.720 \mathrm{~A}$ & $9.991 \mathrm{~B}$ & $6.317 \mathrm{~A}$ \\
\hline $\mathrm{CV}(\%)$ & 6,39 & 11,14 & 12,57 & 16,95 & 13 & 14,36 \\
\hline
\end{tabular}

${ }^{1}$ Médias seguidas pela mesma letra, maiúscula na coluna, não diferem entre si pelo teste de Tukey $(\mathrm{P} \leq 0,05)$. 
TABELA 4. Teores de Proteína Bruta (PB), Fibras em Detergente Ácido (FDA) e Neutro (FDN) de plantas em quatro tratamentos utilizados para produção de silagem na safrinha em Sete Lagoas, MG

\begin{tabular}{lccc}
\hline Tratamento $^{1}$ & PB & FDA & FDN \\
\hline Milheto ADR 500 & $-----1-1$ AB & $36,2 \mathrm{~A}$ & $68,0 \mathrm{AB}$ \\
Milheto BRS 1503 & $6,1 \mathrm{~A}$ & $33,9 \mathrm{~B}$ & $65,1 \mathrm{~B}$ \\
Sorgo com adubação da rebrota & $5,0 \mathrm{BC}$ & $33,0 \mathrm{~B}$ & $69,42 \mathrm{~A}$ \\
Sorgo sem adubação da rebrota & $4,02 \mathrm{C}$ & $32,8 \mathrm{~B}$ & $67,8 \mathrm{AB}$ \\
\hline $\mathrm{CV}(\%)$ & 15,37 & 2,6 & 3,3 \\
\hline
\end{tabular}

${ }^{1}$ Médias seguidas pela mesma letra, maiúscula na coluna, não diferem entre si pelo teste de Tukey $(\mathrm{P} \leq 0,05)$.

$\mathrm{Na}$ avaliação qualitativa da forragem, o teor de fibras solúveis em detergente neutro engloba as porções de hemicelulose, celulose, lignina e sais das células, parâmetros relacionados ao consumo da forragem. Ao passo em que a fibra solúvel em detergente ácido está relacionada indiretamente com a digestibilidade, por envolver o conteúdo de lignina das células (Lana, 2005). Adicionalmente, o teor de proteína bruta está diretamente relacionado à espécie vegetal e à adubação nitrogenada, sendo esse parâmetro positivamente proporcional à produção do rebanho.

Nesse sentido, destaca-se que as plantas de milheto, com produtividade menor de matéria seca em relação ao sorgo da rebrota adubado, produziram quantidade semelhante de proteína bruta. E, entre as duas variedades de milheto, a ADR 500 se mostrou inferior por apresentar maior teor de fibra em detergente ácido, provavelmente em função do melhoramento genético, uma vez que a BRS 1503 foi desenvolvida recentemente (agosto de 2013) pela Embrapa Milho e Sorgo e a ADR 500 é cultivada há décadas no Brasil (Pereira Filho, 2003).

Porém, destaca-se que, em todos os parâmetros relacionados à produtividade, o sorgo quando não adubado se mostrou semelhante às cultivares de milheto, evidenciando as qualidades daquela espécie

TABELA 5. Teor (\%) de Matéria Seca (TMS) e produtividades (kg ha $\left.{ }^{-1}\right)$ de Matéria Seca (PMS), Proteína Bruta (PPB), Fibras Em Detergente Ácido (PFDN) e Neutro (PFDN) de plantas em quatro tratamentos utilizados para produção de silagem na safrinha em Sete Lagoas, MG

\begin{tabular}{lccccc}
\hline Tratamento $^{1}$ & TMS & PMS & PPB & PFDA & PFDN \\
\hline Milheto ADR 500 & $33,52 \mathrm{~A}$ & $6.607 \mathrm{~B}$ & $405 \mathrm{AB}$ & $2.386 \mathrm{~B}$ & $4.471 \mathrm{~B}$ \\
Milheto BRS 1503 & $32,54 \mathrm{~A}$ & $6.969 \mathrm{~B}$ & $488 \mathrm{AB}$ & $2.362 \mathrm{~B}$ & $4.553 \mathrm{~B}$ \\
Sorgo com adubação da rebrota & $32,36 \mathrm{~A}$ & $11.270 \mathrm{~A}$ & $563 \mathrm{~A}$ & $3.723 \mathrm{~A}$ & $7.838 \mathrm{~A}$ \\
Sorgo sem adubação da rebrota & $31,66 \mathrm{~A}$ & $7.266 \mathrm{~B}$ & $293 \mathrm{~B}$ & $2.387 \mathrm{~B}$ & $4.937 \mathrm{~B}$ \\
\hline CV (\%) & 6,16 & 14,89 & 24,72 & 13,88 & 16,14 \\
\hline
\end{tabular}

${ }^{1}$ Médias seguidas pela mesma letra, maiúscula na coluna, não diferem entre si pelo teste de Tukey $(\mathrm{P} \leq 0,05)$. 
como forragem, principalmente em cultivo na safrinha (Almeida Filho et al., 2010) e com condições climáticas adequadas. Finalmente, os resultados ressaltam as respostas da espécie à adubação nitrogenada, conforme relatado por Resende et al. (2009).

Considerando o somatório das produções de forragem nas estratégias avaliadas, em relação à qualidade das forragens, foi verificado que as plantas de sorgo produzidas na safra acumularam maior conteúdo de proteína bruta. Porém, como fator negativo, foi observado também maior conteúdo de FDA. Por outro lado, a adubação da rebrota do sorgo não possibilitou os maiores conteúdos de proteína bruta.

Esse diferenciado teor de proteína nas plantas de sorgo produzidas na safra provavelmente se deve ao fato de as mesmas terem sido colhidas com 17,3\% de matéria seca, uma vez que a colheita do sorgo da rebrota, adubado ou sem adubação, com aproximadamente $30 \%$ de matéria seca, reduziu a média final do teor de proteína, resultado semelhante para os valores de FDA (Tabela 6). Dessa forma, dentre os tratamentos, aqueles que contêm o milho são considerados superiores com relação ao parâmetro FDA.

A produtividade máxima de matéria seca de forragem foi obtida utilizando-se milho na safra e milheto na safrinha ou sorgo na safra seguido de adubação da rebrota. Foi possível o acúmulo de até 27.180 $\mathrm{kg} \mathrm{ha}^{-1}$ quando cultivada a variedade de milheto BRS 1503 após a colheita do milho (Tabela 7).

Porém, vale destacar que a produtividade de matéria seca de sorgo pode ser igual ou superior à do milho. Von Pinho et al. (2007) verificaram produtividade aproximada de $20.000 \mathrm{~kg} \mathrm{ha}^{-1}$ de matéria seca em plantas de sorgo ou milho cultivadas a partir de novembro na região de Lavras, MG. Porém esses autores não recomendam a substituição do milho pelo sorgo em função dos caracteres fitotécnicos das culturas considerando plantios em outras épocas. Por outro lado, Neumann et al. (2004) destacam que o plantio de sorgo significa mais receita líquida na atividade de engorda de bovinos com relação ao milho.

Assim, considerando o menor número de práticas que oneram os custos de produção e menor

TABELA 6. Somatório dos teores de Proteína Bruta (PB), Fibras em Detergente Ácido (FDA) e Neutro (FDN) de plantas cultivadas na safra e na safrinha para produção de silagem em Sete Lagoas, MG

\begin{tabular}{|c|c|c|c|c|}
\hline \multicolumn{2}{|r|}{ Tratamentos $^{1}$} & \multirow{2}{*}{ PB } & \multirow{2}{*}{ FDA } & \multirow{2}{*}{ FDN } \\
\hline Safra & Safrinha & & & \\
\hline & & ----------- & --- \% --- & -----------' \\
\hline Milho & Pousio & $9,34 \mathrm{~B}$ & $34,6 \mathrm{C}$ & $71,3 \mathrm{AB}$ \\
\hline Sorgo & Pousio & $12,42 \mathrm{~A}$ & $45,48 \mathrm{~A}$ & $71,86 \mathrm{~A}$ \\
\hline Milho & Milheto ADR 500 & $8,54 \mathrm{~B}$ & $34,96 \mathrm{C}$ & $70,46 \mathrm{AB}$ \\
\hline Milho & Milheto BRS 1503 & $8,74 \mathrm{~B}$ & $34,42 \mathrm{C}$ & $69,76 \mathrm{~B}$ \\
\hline Sorgo & Com adubação da rebrota & $9,08 \mathrm{~B}$ & $39,86 \mathrm{~B}$ & $70,84 \mathrm{AB}$ \\
\hline Sorgo & Sem adubação da rebrota & $9,46 \mathrm{~B}$ & $41,02 \mathrm{~B}$ & $70,62 \mathrm{AB}$ \\
\hline & $\mathrm{CV}$ & 7,3 & 1,52 & 1,45 \\
\hline
\end{tabular}

${ }^{1}$ Médias seguidas pela mesma letra, maiúscula na coluna, não diferem entre si pelo teste de Tukey $(\mathrm{P} \leq 0,05)$. 
TABELA 7. Somatório das Produtividades de Massa Seca (PMS), Proteína Bruta (PPB), Fibras em Detergente Ácido (PFDA) e Neutro (PFDN) de plantas em diferentes estratégias para produção de silagem em Sete Lagoas, $\mathrm{MG}$

\begin{tabular}{|c|c|c|c|c|c|}
\hline \multicolumn{2}{|r|}{ Tratamentos $^{1}$} & \multirow{2}{*}{ PMS } & \multirow{2}{*}{ PPB } & \multirow{2}{*}{ PFDA } & \multirow{2}{*}{ PFDN } \\
\hline Safra & Safrinha & & & & \\
\hline & & \multicolumn{4}{|c|}{ 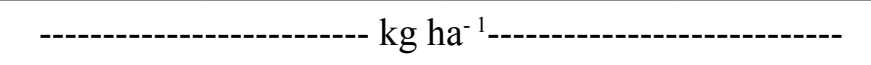 } \\
\hline Milho & Pousio & $20.211 \mathrm{~B}$ & $1.903 \mathrm{BC}$ & $6.991 \mathrm{C}$ & $1.4411 \mathrm{~B}$ \\
\hline Sorgo & Pousio & $13.906 \mathrm{C}$ & $1.720 \mathrm{C}$ & $6.317 \mathrm{C}$ & $9.991 \mathrm{C}$ \\
\hline Milho & Milheto ADR 500 & $26.818 \mathrm{~A}$ & $1.308 \mathrm{~A}$ & $9.377 \mathrm{AB}$ & $18.881 \mathrm{~A}$ \\
\hline Milho & Milheto BRS 1503 & $27.180 \mathrm{~A}$ & $2.391 \mathrm{~A}$ & $9.353 \mathrm{AB}$ & $18.963 \mathrm{~A}$ \\
\hline Sorgo & Com adubação da rebrota & $25.176 \mathrm{~A}$ & $2.283 \mathrm{AB}$ & $10.039 \mathrm{~A}$ & $17.828 \mathrm{~A}$ \\
\hline Sorgo & Sem adubação da rebrota & $21.172 \mathrm{~B}$ & $2.013 \mathrm{ABC}$ & $8.703 \mathrm{~B}$ & $14.927 \mathrm{~B}$ \\
\hline \multicolumn{2}{|r|}{$\mathrm{CV}$} & 6,89 & 9,63 & 7,32 & 6,98 \\
\hline
\end{tabular}

${ }^{1}$ Médias seguidas pela mesma letra, maiúscula na coluna, não diferem entre si pelo teste de Tukey $(\mathrm{P} \leq 0,05)$.

quantidade de insumos utilizados, em especial plantio e sementes respectivamente, a utilização de sorgo forrageiro, associado à prática de adubação da rebrota, é considerada a mais positiva dentre as avaliadas neste trabalho. Foram observados, para esse tratamento, os maiores valores em produtividade de matéria seca e proteína bruta e produções semelhantes (aos tratamentos com milheto) de fibras. Essas variações nos parâmetros qualitativos não foram, portanto, muito significantes em função das recomendações técnicas (Lana, 2005).

Além dos maiores custos com sementes, adubação de plantio e tratos iniciais, a estratégia de utilizar milheto após o cultivo do milho envolve o risco da não ocorrência de chuvas no momento de sua implantação, entre a segunda quinzena de janeiro e a primeira semana de fevereiro (Ferreira \& Souza, 2011), conforme também observado neste trabalho (Figuras 1 e 2). Nesse período, a depender da época de plantio, existe grande possibilidade de o milheto estar em estádio D2, em que a falta de água compromete o acúmulo de biomassa (Durães \& Magalhães, 2005). Por outro lado, nas plantas de sorgo já estabelecidas os efeitos desse veranico seriam minimizados.

Destaca-se que a adubação nitrogenada utilizada no sorgo da rebrota foi a mesma utilizada no cultivo de milheto (47 $\mathrm{kg} \mathrm{ha}^{-1}$ de N), mas nessa cultura também foi adicionada adubação de plantio. Nesse sentido, avaliando-se os gastos apenas com o adubo, atualmente na região Central de Minas Gerais o N na forma de ureia foi comercializado na safra 2012/13 a $\mathrm{R} \$ 2.800,00$ a tonelada, de acordo com empresas vendedoras da região. A adição de $47 \mathrm{~kg} \mathrm{ha}^{-1}$ de $\mathrm{N}$ possibilitou acréscimo de matéria seca maior que $4.000 \mathrm{~kg} \mathrm{ha}^{-1}$ ao sorgo em relação àquele não adubado e $270 \mathrm{~kg} \mathrm{ha}^{-1}$ de proteína bruta, cerca de 55 e $92 \%$ respectivamente.

Considerando ainda que os pecuaristas pagam cerca de R\$120,00 para cada tonelada de silagem, observa-se que, com a adubação de cobertura no sorgo, verificou-se um incremento de $\mathrm{R} \$ 1.500,00$ por hectare frente a um investimento em ureia de $\mathrm{R} \$ 132,00$ 
$\mathrm{ha}^{-1}$ à propriedade, considerando que $4.000 \mathrm{~kg}$ de matéria seca correspondem a aproximadamente 12,5 toneladas de silagem. As despesas com a adubação de cobertura ainda devem contemplar os gastos com equipamentos e mão-de-obra. No entanto, essa variável é dependente do grau tecnológico de cada propriedade e o preço do adubo é sempre maior e pode chegar a $41 \%$ do custo de produção de sorgo, sendo que a adubação nitrogenada de cobertura representa cerca de 10,2\% (Neumann et al., 2005).

\section{Conclusões}

Dentre as estratégias avaliadas para a produção de forragem na região Central de Minas Gerais, os plantios de milho em safra mais milheto na safrinha e sorgo na safra mais rebrota, com adubação nitrogenada, proporcionaram as maiores produções de forragem. Essas estratégias foram similares com relação aos atributos nutricionais. Finalmente, recomenda-se o plantio de sorgo seguido de condução da rebrota com adubação nitrogenada devido à menor dependência de insumos e práticas de manejo.

\section{Agradecimentos}

À Embrapa Milho e Sorgo, à Capes/PNPD e à Fapemig, pelos suportes financeiro e técnico na realização dos trabalhos.

\section{Referências}

ALMEIDA FILHO, J. E.; TARDIN, F. D.; SOUZA, A.; GODINHO, V. P. C.; CARDOSO, M. J. Desempenho agronômico e estabilidade fenotípica de híbridos de sorgo granífero. Revista Brasileira de Milho e Sorgo, Sete
Lagoas, v. 9, n. 1, p. 51-64, 2010

AZEVEDO, R. A.; FELIX, T. M.; PIRES JÚNIOR, O. S.; ALMEIDA, A. C.; DUARTE, E. R. Perfil de Propriedades Leiteiras ou com Produção Mista no Norte de Minas Gerais. Revista Caatinga, Mossoró, v. 24, n. 1, p. 153-159, 2011.

BATISTELLA，M.; ANDRADE，R. G.; BOLFE, É. L.; VICTORIA, D. C.; SILVA, G. B. S. Geotecnologias e gestão territorial da bovinocultura no Brasil. Revista Brasileira de Zootecnia, Brasília, DF, v. 40, p. 251-260, 2011. Suplemento.

BENETT, C. G. S., BUZETTI, S.; SILVA, K. S.; BERGAMASCHINE' A. F.; FABRICIO, J. A. Produtividade e Composição Bromatológica do Capim-Marandu a Fontes e Doses de Nitrogênio. Ciência e Agrotecnologia, Lavras v. 32, p. 1629-1636, 2008.

BERNARDES, T. F.; CASAGRANDE, D. R.; LARA, M. A. S.; LIMA, L. M.; SILVA, N. C. Produção e uso de silagens em fazendas leiteiras em três mesorregiões do Estado de Minas Gerais. Revista de Ciências Agrárias, Recife, v. 56, n. 2, p. 133-138, 2013

BORGES, L. R.; FONSECA, L. M.; MARTINS, R. T.; OLIVEIRA, M. C. P. P. Milk quality according to the daily range in farm production in the Mesoregion Central Mineira and Oeste of Minas Gerais regions, Brazil. Arquivo Brasileiro de Medicina Veterinária e Zootecnia, Belo Horizonte, v. 65, n. 4, p. 1239-1246, 2013

DIAS, P. F.; ROCHA, G. P.; ROCHA FILHO, R. R. Produção e valor nutritivo de gramíneas forrageiras tropicais, avaliadas no período das águas, sob diferentes doses de nitrogênio. Ciência e Agrotecnologia, Lavras, v. 24, n. 1, p. 260-271, 2000. 
DURAES, F. O. M.; MAGAlHAES, P. C. Ecofisiologia do milheto. In: NETTO, D. A. M.; DURAES, F. O. M. (Ed.). Milheto: tecnologias de produção e agronegócio. Brasília, DF: Embrapa Informação Tecnológica, 2005. cap. 4, p. 93-120.

FERREIRA, W. P. M.; SOUZA, C. F. Caracterização Climática das Séries Temporais de Temperatura e Precipitação Pluvial em Sete Lagoas, MG. Sete Lagoas: Embrapa Milho e Sorgo, 2011. 34 p. (Embrapa Milho e Sorgo. Boletim de Pesquisa e Desenvolvimento, 35).

LANA, R. P. (Ed.). Nutrição e Alimentação Animal (Mitos e Realidades). Viçosa: UFV, 2005. 344 p.

LOPES, M. A.; SANTOS, G.; RESENDE, M. C.; CARVALHO, F. M.; CARDOSO, M. G. Estudo da Rentabilidade de Sistemas de Produção de Leite no Município de Nazareno, MG. Ciência Animal Brasileira, Goiânia, v. 12, n. 1, p. 5869, 2011.

NEUMANN, M.; RESTLE, J.; BRONDANI, I. L. Avaliação de silagens de sorgo (Sorghum bicolor, L. Moench) ou milho (Zea mays, L.) na produção do novilho superprecoce. Revista Brasileira de Milho e Sorgo, Sete Lagoas, v. 3, n. 3, p. 438-452, 2004.

NEUMANN, M.; RESTLE, J.; FILHO, D. C. A.; MACCARI, M.; PELLEGRINI, L. G.; SOUZA, A. N. M.; PEIXOTO, L. A. O. Produção de forragem e custo de produção da pastejo contínuo. Revista Brasileira de Agrociência, Pelotas, v. 11, n. 2, p. 215-220, 2005

NUSSIO, L. G.; MANZANO, R. P.; PEDREIRA, C. G. S. Valor alimentício em plantas do gênero Cynodon. In: SIMPÓSIO SOBRE MANEJO DA PASAGEM, 15. 1998, Piracicaba. Anais...
Piracicaba: FEALQ/ESALQ, 1998, p. 203-242. OLIVEIRA, L. B.; PIRES, A. J. V.; CARVALHO, G. G. P.; RIBEIRO, L. S. O.; ALMEIDA, V. V.; PEIXOTO. C. A. M. Perdas e valor nutritivo de silagens de milho, sorgo-sudão, sorgo forrageiro e girassol. Revista Brasileira de Zootecnia, Viçosa, v. 39, n. 1, p. 61-67, 2010.

PAZIANI, S. de F.; DuarteA. P; Nussio L. G.; Gallo, P. B.; Bittar C. M. M.; Zopollatto M.; Reco, P. C. ${ }^{I}$ Características agronômicas e bromatológicas de híbridos de milho para produção de silagem.

Revista Brasileira de Zootecnia, Viçosa, v.38, n. 3, p. 411-417, 2009.

PEREIRA FILHO, I. A.; FERREIRA, A. da S.; COELHO, A. M.; CASELA, C. R.; KARAM, D.; RODRIGUES, J. A. S.; CRUZ, J. C.; WAQUIL, J. M. Manejo da Cultura do Milheto. Sete Lagoas: Embrapa Milho e Sorgo, 2003. 17 p. (Embrapa Milho e Sorgo. Circular Técnica, 29)

PORTO, P. P.; SILVA, C. S.; ARTACHO, L.; PISTELli, A. P.; CONSTANTINO, C. Aspectos quantitativos da carcaça de cordeiros mestiços suplementados com silagem de milho ou milheto. Synergismus scyentifica, Pato Branco, v. 7. n. 1, 2012

RESENDE, A. V.; COELHO, A. M.; RODRIGUES, J. A. S.; SANTOS, F. C. Adubação maximiza o potencial produtivo do sorgo. Sete Lagoas: Embrapa Milho e Sorgo, 2009. 8 p. (Embrapa Milho e Sorgo. Circular técnica, 119) RIBEIRO, A. C.; GUIMRÃES, P. T. G.; ALVAREZ V., V. H.. (Ed.). Recomendações para uso de corretivos e fertilizantes em Minas Gerais -

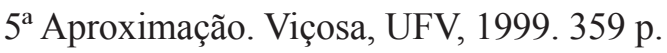

PERFIL do Agronegócio: 2003-2009. Belo Horizonte: Secretaria de Estado de Agricultura, Pecuária e 
Abastecimento de Minas Gerais, [2010]. 142 p. SILVA, A. G.; BARROS, A. S.; TEIXEIRA, I. R. Avaliação agronômica de cultivares de sorgo forrageiro no sudoeste do estado de Goiás em 2005. Revista Brasileira de Milho e Sorgo, Sete Lagoas, v. 6, n. 1, p. 116-127, 2007

SILVA, D. J.; QUEIROZ, A. C. Análise de alimentos: métodos químicos e biológicos 3. ed. Viçosa, MG: UFV, 2006. 235 p.

VAN SOEST, P. J.; ROBERTSON, J.B.; LEWIS, B.A. Symposium: Carbohydrate methodology, metabolism, and nutritional implications in dairy cattle. Methods for dietary fiber, neutral detergent fiber, and nonstarch polysaccharides in relation to animal nutrition. Journal of Dairy Science, Champaign, v.74, n.10, p.35833597, 1991.

VON PINHO, R. G.; VASCONCELOS, R. C.; BORGES, I. D.; RESENDE, A.V. Produtividade e qualidade da silagem de milho e sorgo em função da época de semeadura. Bragantia, Campinas, v. 66, n. 2, p. 235-245, 2007. 